\title{
FORMAÇÃO DE PROFESSORES DE INGLÊS NO BRASIL
}

\author{
English teachers education in Brazil
}

\author{
Ana Maria Ialago ${ }^{a}$, Marilia Claret Geraes Duran ${ }^{\mathrm{b}}$ \\ a Mestre em Educação do PPG em Educação da Universidade Metodista de São \\ Paulo, São Paulo, SP - Brasil. e-mail: ami@ccaa-abc.com.br \\ b Docente Pesquisadora do PPG em Educação da Universidade Metodista de São Paulo, \\ São Paulo, SP - Brasil. e-mail: marilia.duran@metodista.br
}

\section{Resumo}

Os desafios relativos à formação de professores são temas recorrentes - e relevantes - nas discussões acadêmicas atuais. Este artigo tem como objetivo apresentar algumas reflexões a este respeito, centrando a discussão nos processos formativos de professores de língua inglesa, a partir da análise de material colhido num estudo sobre representações sociais que tais profissionais têm a respeito do idioma que ensinam, de sua formação e de sua prática docente.

Palavras-chave: Formação; Licenciatura em inglês; Representações sociais. 


\section{Abstract}

Nowadays, the challenges related to teacher education are recurrent - and relevant - issues in academic discussions. This article presents some reflections upon this topic, focusing the discussion upon the educational process of English language teachers. Such reflections are based on data gathered for a study of the social representations that English teachers have about the language itself, their educational processes as well as their pedagogical practices.

Keywords: Teacher education; Licentiateship in english; Social representations.

A formação de professores tornou-se tema recorrente nas discussões acadêmicas dos últimos trinta anos, a partir especialmente da década de 1990 , possibilitando um debate fundamentado em pesquisas empíricas e teóricas e, portanto, um debate mais qualificado sobre o tema. Apesar do crescimento expressivo da pesquisa universitária e da produção editorial no campo da formação de professores, trazendo reflexões acerca da importância do professor, muito pouco se faz para mudar a condição de sua formação, oferecendo um currículo comprometido com a profissionalidade e o profissionalismo docente. Bourdoncle (1991, p. 92-94), citado por Ludke e Boing (2004, p. 1173), propõe uma tripla distinção entre profissionalidade, profissionismo e profissionalismo, no campo do estudo das profissões. Profissionalidade, termo de origem italiana e introduzido no Brasil pela via francesa, está associado às instabilidades e ambigüidades que envolvem o trabalho em tempos neoliberais e geralmente vem colocado como uma evolução da idéia de qualificação, Profissionismo ou corporatismo são neologismos ligados a estratégias e retóricas coletivas que tentam transformar uma atividade em profissão. O terceiro conceito explicado por Bourdoncle, de "profissionalismo", é marcado pela adesão individual à retórica e às normas da corporação. Para o autor, é nesse estágio que realmente começa a socialização profissional. O que distingue essa dimensão das anteriores é a escolha pessoal que se faz pela profissão. Estas distinções trazem uma contribuição importante nas discussões que propomos, considerando o contexto formativo de professores de inglês no Brasil.

Destacamos, então, duas questões, aparentemente óbvias, como ponto de partida dessas reflexões, para enfatizar a complexidade de tais processos:

De um lado, o contexto em que se situa a problemática da formação de professores, a descaracterização e a desvalorização social da educação em

Rev. Diálogo Educ., Curitiba, v. 8, n. 23, p. 55-70, jan./abr. 2008 
geral e do professorado em particular, com a decorrente diminuição das matrículas em vários cursos de licenciatura, considerando as dificuldades do mercado de trabalho e a parca remuneração do magistério que vêm acentuando o seu caráter de atividade marginal ou provisória. Assim, o magistério (em especial, o magistério na Educação Básica) vem se constituindo mais como uma contingência do que como uma opção e os cursos de Licenciatura em geral representam, muitas vezes, uma possibilidade mais fácil de obtenção de um diploma universitário.

De outro lado, as pesquisas com os alunos egressos das Licenciaturas evidenciam o baixo nível de satisfação dos licenciados com a formação profissional recebida, enfatizando que seus professores deveriam dar maior atenção ao processo ensino-aprendizagem, maior ênfase à realidade educacional brasileira com a análise dos problemas concretos da sala de aula e propondo a revisão dos estágios supervisionados com ênfase na relação teoria-prática, numa perspectiva que entende que a teoria se constrói da prática.

Aliás, esta não é uma questão nova. Estudo longitudinal realizado entre os anos 1993-1996, acompanhando o desenvolvimento formativo de uma turma do Curso de Pedagogia de uma instituição particular, mostra claramente que existem outras motivações, que não de natureza material, que correspondem ao que Adorno (1995) caracterizou como motivações subjetivas da aversão contra o Magistério, em especial os chamados "tabus", as representações inconscientes dos eventuais candidatos ao Magistério e que talvez expliquem a existência de uma ambigüidade na opção por esta profissão (DURAN; JÚLIO, 1997, p. 13).

As grandes lacunas formativas, observadas nas pesquisas, no que se refere aos cursos de licenciatura, além dos conteúdos próprios, apontam para a inadequação na realização de estágios, como afirma Gatti (2003, p. 475):

Como se o professor pudesse ser professor sem ter refletido sobre educação, sobre o desenvolvimento de crianças e jovens, sem ter feito um estágio adequado, sem ter permanecido o tempo necessário em uma escola, sem ter acompanhado o trabalho de outro professor, sem ter tido a chance de ensaiar um trabalho com crianças ou adolescentes.

Em relação à própria escolha da profissão de professor - "ser professor no Brasil" está ligado a uma diversidade de relações que marcam cada percurso profissional de modo particular: desde o ingresso na carreira - por gosto, por opção, por "vocação", para suprir necessidades financeiras pessoais e familiares. Geralmente o ingresso ocorre ou muito cedo, para "ganhar a vida", para "ajudar os pais", ou mais tarde, "para complementar a renda familiar", ou como segundo 
emprego. No entanto, ainda citando Gatti: "Não se coloca as conseqüências de uma formação fragmentária e precária de um professor para uma sociedade tão complexa, para uma atuação tão complexa [...] e que não é valorizada devidamente" (GAT'TI, 2003, p. 475).

Discutir sobre a necessidade de uma reconfiguração da formação de professores, no âmbito das licenciaturas, considerando o evidente esgotamento da alternativa tradicional de ensinar/aprender, mas considerando que nesse espaço não há lugar nem para o espontaneísmo, nem para a acomodação, levou ao desenvolvimento deste trabalho. De fato, três aspectos vêm sendo destacados como lacunas formativas nas licenciaturas em geral: ausência de um perfil profissional do docente a ser formado; falta de integração entre áreas de conteúdo e disciplinas pedagógicas e formação dos formadores.

Neste artigo, estaremos problematizando tais questões no que se refere à formação de professores de inglês, considerando sua especificidade quanto ao reconhecido valor funcional, cultural e formativo do aprendizado de uma língua estrangeira. Na verdade, as sociedades, ao longo dos séculos e dependendo das condições sociais, políticas e, principalmente, das condições econômicas do momento histórico em questão, ditavam, e ditam ainda hoje, qual língua deve ser considerada "franca", estabelecendo os motivos para que os indivíduos busquem aprender um novo idioma.

\section{O inglês na sociedade brasileira}

Nos dias atuais, em virtude da condição hegemônica que os Estados Unidos exercem no cenário mundial, o conhecimento da língua inglesa é altamente valorizado. Sendo o segundo idioma mais falado no mundo, o inglês é hoje o idioma utilizado na maioria das relações comerciais, sendo também veículo preferencial para a transmissão de descobertas científicas e tecnológicas.

A escolha do inglês como língua franca do mundo globalizado não foi obra do acaso, nem foi resultado de fundamentos fonéticos ou gramaticais próprios desse idioma, o que traz a discussão do seu ensino para uma perspectiva social, como evidencia o excerto do trabalho de Crystal (apud ORTIZ, 2006, p. 24), transcrito a seguir:

Uma língua não se torna global por causa de suas propriedades estruturais, pelo tamanho de seu vocabulário, por ser veículo de uma grande literatura do passado, ou por ter sido associada a uma grande cultura ou religião [...]. Uma língua torna-se internacional por uma razão maior: o poder político de seu povo - especialmente seu poderio militar. O poder militar de uma nação pode impor

Rev. Diálogo Educ., Curitiba, v. 8, n. 23, p. 55-70, jan./abr. 2008 
uma língua, mas é necessário um poder econômico para mantê-la e expandi-la [...]. O crescimento dos negócios e de uma indústria competitiva trouxe uma explosão internacional do marketing e do business [...]. A tecnologia, na forma do cinema e dos discos, canalizou as novas formas de entretenimento de massa o que teve impacto mundial. O impulso no progresso da ciência e da tecnologia criou um ambiente internacional de pesquisa conferindo ao conhecimento acadêmico um alto grau de desenvolvimento. Qualquer língua, no centro desta explosão de atividades internacionais, repentinamente, teria sido alçada a um status global.

Embora diferentes situações sociais e econômicas tenham privilegiado ora um ora outro idioma, por muitos séculos, o estudo de línguas estrangeiras tem privilegiado a habilidade de leitura, baseando-se na compreensão dos fundamentos da gramática e na tradução. Esta forma de pensar o ensino de uma língua estrangeira foi derivada da metodologia utilizada para o ensino de línguas clássicas como o grego e o latim, com o objetivo do entendimento e da produção de textos escritos. De certo modo, tal escolha pode ter sido adequada enquanto a maior parte da comunicação era realizada na forma escrita, ficando a comunicação oral a cargo de alguns poucos intérpretes. E enquanto a educação era dirigida para uma alta camada da sociedade, com a finalidade de preparar os indivíduos para participarem, cultural e socialmente, da elite à qual pertenciam, de fato, tal escolha também parecia adequada.

Com a modernização da economia, em tempos de globalização, o domínio da língua inglesa passou a representar um grande diferencial nas relações competitivas do mercado de trabalho, ampliando as necessidades da aquisição de uma segunda língua - o inglês. Outro aspecto a ser considerado neste contexto diz respeito ao desenvolvimento da tecnologia que possibilita hoje em dia o rápido deslocamento das pessoas, bem como a comunicação instantânea, tanto na forma escrita quanto na forma oral.

E, neste cenário, uma abordagem tradicional de ensino de língua estrangeira moderna torna-se inadequada, surgindo novos desafios para os profissionais responsáveis por esta atividade.

\section{O ensino de inglês na educação formal}

No Brasil, a educação reconhece o valor cultural do aprendizado de línguas estrangeiras, ao incluir seu estudo no currículo oficial. Na prática, porém, uma série de fatores inviabiliza sua realização: professores com pouco domínio

Rev. Diálogo Educ., Curitiba, v. 8, n. 23, p. 55-70, jan./abr. 2008 
oral da língua, salas numerosas, carga horária reduzida, entre outros, fazem com que o ensino de uma língua estrangeira moderna permaneça centrado na leitura, no vocabulário e na gramática, sem a devida atenção à habilidade oral.

Ao realizar trabalhos de pesquisa e de formação continuada com professores de inglês da rede pública, Vera Lúcia Menezes Paiva (2003, p. 53-84), da Universidade Federal de Minas Gerais, pontuou ainda outras questões que merecem uma reflexão para um melhor entendimento da problemática.

Uma primeira, relacionada aos aspectos legais, por exemplo, a Lei de Diretrizes e Bases de 1961 e a Lei n. 5.692, de 1971, que não incluíram o inglês entre as disciplinas obrigatórias, sendo seu ensino apenas recomendado, deixando a cargo dos Conselhos Estaduais decidirem sobre o ensino de línguas. A atual Lei de Diretrizes e Bases n. 9394, de 1996, define a obrigatoriedade de uma língua estrangeira moderna, a ser escolhida pela comunidade escolar, mas, na prática, muito pouco é feito para que ela seja ensinada com sucesso, ou que o profissional responsável por seu ensino seja bem formado.

Outra questão apontada por Paiva (2003, p. 53-84) relaciona-se à prática escolar. Ou seja, a autora conclui que muitas vezes é desta própria prática que surgem as sementes de uma crença, muito arraigada no meio escolar, de que não é possível aprender línguas na escola regular. Vários profissionais sentem-se inseguros quanto ao conteúdo da disciplina que ensinam, e sentem-se desprestigiados pela forma como ela é encarada, pois suas aulas são colocadas nos piores horários, ou reuniões são marcadas no horário delas, gerando seu cancelamento.

A autora destaca, ainda, em relação à formação inicial dos professores de inglês que, em geral, os cursos de licenciatura em língua estrangeira estão atrelados às licenciaturas em língua portuguesa, cujos conteúdos ocupam a maior parte da grade curricular. Por questões de mercado e de concorrência, empresários da educação oferecem cursos de três anos, nos quais as duas licenciaturas são "empacotadas", o que impossibilita, entre outras coisas, o desenvolvimento da competência comunicativa do professor.

Percebe-se, a partir da leitura dos trabalhos de Paiva, que o sistema educacional brasileiro coloca no mercado de trabalho professores despreparados, os quais nem sempre têm a oportunidade de participar de programas de formação continuada como os desenvolvidos pela pesquisadora citada. Com uma formação praticamente inexistente para o ensino da língua estrangeira, esse profissional prepara os futuros alunos de licenciatura, os quais chegarão à faculdade sem um conhecimento sólido da língua inglesa, fechando, assim, um círculo que se realimenta e que dá origem à crença de que não é possível aprender inglês na escola.

Modificar esta situação constitui-se num desafio e é nesse sentido que este artigo pretende trazer contribuições, ao propor uma reflexão sobre a formação do professor de língua inglesa, no seguinte sentido: a língua inglesa,

Rev. Diálogo Educ., Curitiba, v. 8, n. 23, p. 55-70, jan./abr. 2008 
na sociedade atual, como instrumento de inserção e ascensão no mercado de trabalho, orienta/tem orientado as relações e as condutas de profissionais responsáveis por sua atividade? Quais são os desafios da formação de professores de língua inglesa, no Brasil?

Na verdade, a bibliografia disponível sobre o tema, embora ainda restrita às questões do ensino de língua inglesa no Brasil, aponta para os sérios desafios que precisa vencer, entre eles, a forma como tal ensino é encarado pelas autoridades educacionais. Uma leitura atenta dos documentos oficiais torna visível que o ensino de idiomas é visto como algo pouco relevante, ficando à margem dos grandes projetos pedagógicos.

Um exemplo de tal visão pode ser encontrado nas considerações preliminares dos Parâmetros Curriculares Nacionais de Língua Estrangeira publicada pelo MEC em 1998, onde se lê que:

Deve-se considerar também o fato de que as condições na sala de aula da maioria das escolas brasileiras (carga horária reduzida, classes superlotadas, pouco domínio das habilidades orais por parte da maioria dos professores, material didático reduzido ao giz e livro didático, etc.) podem inviabilizar o ensino das quatro habilidades comunicativas. Assim, o foco na leitura pode ser justificado em termos da função social das LES no país e também em termos dos objetivos realizáveis tendo em vista as condições existentes.

Um possível desdobramento desta visão oficial é a maneira como a formação dos profissionais responsáveis pelo ensino de língua estrangeira moderna é realizada em muitos dos cursos de Letras do país.

A primeira grande dificuldade encontrada pelos formadores, ou seja, o fato de que a maioria dos alunos chega à faculdade sem um conhecimento sólido da língua estrangeira para a qual buscam a licenciatura vem sendo muito discutida, havendo vasto material disponível a respeito. O objetivo aqui é discutir o porquê, mesmo entre os poucos alunos que chegam à graduação com um nível adequado de fluência em língua estrangeira, sentem-se frustrados com a formação que lhes é oferecida, a qual, segundo eles, não os prepara adequadamente para os desafios da sala de aula. ${ }^{1}$

Pesquisas como a de Paiva (2003, p. 53-84) apontam para o fato de que em muitas Faculdades de Letras do país, em função da prática da dupla licenciatura, a formação do professor de inglês fica a cargo de pedagogos, os

1 Conforme relatado por Biazzoto (2004), Branco (2005) e Chimin (2003). Ver referências bibliográficas.

Rev. Diálogo Educ., Curitiba, v. 8, n. 23, p. 55-70, jan./abr. 2008 
quais nem sempre têm familiaridade com conceitos de lingüística aplicada. Esses profissionais discutem em suas aulas teorias de aprendizagem mais gerais, as quais são importantíssimas para a formação do docente, mas que nem sempre dão conta de questões específicas dos processos de ensino/aprendizagem de uma língua estrangeira.

Outra tendência verificada nestes cursos é uma visão dogmática do professor de línguas, focada no ensino de técnicas de ensino, como nos informa Moita Lopes (1996, p. 179-180):

Embora os cursos de formação de professores de línguas variem no que se refere à ênfase que colocam em um tipo de competência ou em outra devido a uma série de fatores (estafe especializado disponivel, carga horária dos cursos, etc.), igualmente se ressentem de uma base teórica explícita sobre os processos de uso da linguagem dentro e fora da sala de aula. Ou seja, a formação que os professores recebem não lhes permite fazer escolhas sobre o quê, o como e o porquê ensinar que sejam informadas teoricamente. Em geral, no que se refere a questões de uso da linguagem em sala de aula, os professores são treinados na utilização de técnicas, típicas de métodos específicos de ensino, sem que lhes seja dado o conhecimento de natureza teórica sobre a linguagem em uso na sala de aula [...]. Isso quer dizer que são treinados a partir de certos modismos sobre como ensinar línguas, isto é, recebem sua formação pautada por dogmas.

O descolamento entre as disciplinas pedagógicas e as questões relativas ao conteúdo parece impossibilitar a formação de profissionais competentes, dos quais se espera, além do domínio do conteúdo (condição básica), que tenham também maturidade para refletir sobre sua ação pedagógica e possam fazer escolhas informadas sobre como ensiná-lo.

Alarcão (1998, p. 21-28) traz uma reflexão significativa neste sentido, ao traçar um paralelo entre a competência lingüística comunicativa que se procura desenvolver nos alunos de língua estrangeira e a competência pedagógica comunicativa que se espera desenvolver nos futuros professores de língua estrangeira moderna. Recorrendo à Schulman (1986, p. 4-14) e Schön (2000), a autora discute a importância - em virtude da natureza das funções desenvolvidas pelo professor de língua estrangeira - que este profissional seja não somente proficiente na língua, mas também conheça as ciências da educação e da linguagem.

Rev. Diálogo Educ., Curitiba, v. 8, n. 23, p. 55-70, jan./abr. 2008 
Naturalmente, no curto espaço de tempo de uma graduação, não é possível conceber que os alunos venham a obter um profundo conhecimento do conteúdo (content knowledge), ${ }^{2}$ ou seja, um alto nível de proficiência da língua. Esta competência precisa, necessariamente, ser alcançada em outro momento e espaço. Mas a graduação poderia ocupar-se mais detidamente sobre questões do domínio da língua enquanto objeto de aprendizagem (pedagogical content knowledge), ao discutir a dimensão do conhecimento para o ensino, não no sentido do saber pedagógico generalizado como tratado nas aulas de prática de ensino, mas numa discussão de teorias de aprendizagem e didáticas próprias para o ensino da língua estrangeira, buscando respaldo nas ciências da lingüística e da lingüística aplicada.

\section{Professores de inglês: o que dizem, como pensam o processo formativo}

Para aprofundar as questões acima, foi realizada uma pesquisa entre profissionais que atuam numa rede de idiomas do Grande ABC. A seleção foi orientada por ser o local de trabalho da pesquisadora e por contar com profissionais com formação acadêmica e experiência docente distintas. Um questionário inicial foi entregue aos 158 professores de inglês da instituição, havendo um retorno de 79.

Dos 158 professores envolvidos na pesquisa, apenas 59 deles possuíam formação específica para a docência, de acordo com os registros da instituição na qual trabalham. Isso significa que representam somente $37,35 \%$, contra os $62,65 \%$ de profissionais com formação diversificada. Foi interessante notar que, embora minoria na instituição, foram os que participaram mais significativamente na pesquisa, somando $55,7 \%$ dos respondentes contra apenas $44,3 \%$ de respondentes entre os profissionais com formação diversificada. Tal fato parece confirmar a tendência apontada pelo estudo de Marzari (2005, p. 56-69) do maior nível de comprometimento sinalizado pelos profissionais com formação específica.

A partir da análise dos dados obtidos por meio deste instrumento, foi possível selecionar temas para o roteiro de uma entrevista em profundidade, escolhidos por sua "relevância teórica" (FRANCO, 2003, p. 16), ou seja, por oferecer possibilidades de acesso à teoria que orienta a concepção de realidade

2 Segundo Schulman (1986), o content knowledge refere-se à quantidade e organização do conteúdo em si na mente do professor, enquanto o pedagogical content knowledge vai para além do conteúdo em si, para a dimensão do conhecimento de conteúdo para o ensino. Esse conhecimento engloba questões tais quais abordagens ou metodologias de ensino, mas preocupa-se também com a capacidade do professor de representar e apresentar o conteúdo de forma compreensível para os alunos, a partir do entendimento de fatores que possam auxiliar ou dificultar o aprendizado de um determinado conteúdo, como, por exemplo, conceitos e pré-conceitos que alunos de diferentes idades e classes sociais trazem consigo para a sala de aula.

Rev. Diálogo Educ., Curitiba, v. 8, n. 23, p. 55-70, jan./abr. 2008 
dos sujeitos (FRANCO, 2003, p. 22). Neste artigo destacamos os dados colhidos nas entrevistas junto a profissionais com formação específica (curso de Letras) e com experiência no ensino formal, e as contribuições que eles trouxeram para uma reflexão sobre os processos de ensino e aprendizagem da língua inglesa na educação formal, em especial no que se refere ao curso de Licenciatura.

Uma primeira análise dos dados permitiu a constatação de que as respostas à questão, "Por que decidiu ser professor de inglês?", foram, em sua maioria, paixão, dom ou vocação, palavras que expressavam os sentimentos dos sujeitos em relação ao idioma e à profissão e serão essas as respostas consideradas e problematizadas neste trabalho.

A teoria das Representações Sociais (MOSCOVICI, 1978; JODELET, 2005) orientou a pesquisa desenvolvida, na perspectiva de contribuir para uma discussão a respeito dos desafios da formação de professores de língua inglesa, no Brasil.

Para Denise Jodelet (2005, p. 50), representações sociais são:

[...] uma forma de pensamento social, cuja gênese, propriedades e funções devem ser relacionadas com os processos que afetam a vida e a comunicação sociais, com os mecanismos que concorrem para a definição da identidade e a especificidade dos sujeitos sociais, indivíduos ou grupos, assim como a energética que está na origem da relação que estes grupos mantêm entre si.

Ampliando esta questão, Jodelet (2005, p. 39-40) evidencia que as representações sociais são essenciais para uma compreensão de como os profissionais estão situados socialmente e como, enquanto "teorias socialmente criadas e operantes", relacionam-se com as condições da realidade cotidiana, surgindo a partir das condutas e comunicações realizadas por uma determinada comunidade e influenciando as expressões e práticas dos grupos sociais no seio dos quais são elaboradas e para os quais retornam.

Considerando, como afirma Marková (2006a, p. 270), que “aprender uma linguagem não significa aprender somente vocabulário e gramática, mas também os gêneros [e que quando] adotamos os gêneros, temos também que adotar os estilos de pensamento", a aprendizagem de uma língua estrangeira, por tratar-se de um processo intimamente ligado à adoção de novos estilos de pensamento parece encaminhar para a pertinência de se investigar as "teorias" que embasam as práticas docentes dos professores de língua inglesa.

Se, por um lado, a aprendizagem de uma determinada língua pode resultar numa experiência educacional ampliadora e libertadora, por outro, pode também estar apenas a serviço de um processo de divulgação de uma determinada

Rev. Diálogo Educ., Curitiba, v. 8, n. 23, p. 55-70, jan./abr. 2008 
cultura, de uma determinada visão de mundo, de uma determinada ideologia. Ou seja, estamos aqui assumindo que a posição dos profissionais responsáveis por seu ensino pode ser decisiva nos resultados obtidos. O aprendizado de uma língua estrangeira pode estar alinhado a uma preocupação tecnicista, utilitária ou pode auxiliar o aluno a tornar-se co-autor de seu discurso social.

As respostas dos professores pesquisados apontaram o seu distanciamento de questões mais sociais e reflexivas da própria prática docente. Tais respostas indicaram que a sedução do indivíduo pela língua inglesa é uma questão importante no processo de ensino/aprendizagem do idioma. Os profissionais relataram ${ }^{3}$ seu próprio envolvimento emocional com a língua, como se pode verificar nos seguintes trechos da entrevista:

Prof. 1: Eu tomei contato com a língua inglesa quando eu era adolescente, de assistir filmes e ouvir música., então eu queria entender, eu queria saber o que se passava porque era uma língua totalmente diferente.

Prof. ${ }^{a} 2$ : Desde criança eu tive vontade de aprender no curso [...]. Abriu um (nome da instituição) aqui em (cidade) e eu fiquei infernizando meu pai, 'pai, eu quero; pai, eu quero'.

É importante observar, inclusive, que alguns professores lançaram mão de "vozes coletivas" para dar sustentação à sua própria resposta. Em vários momentos, é possível entrever a fala do "third party' as an 'inside' feature of the dialogue" (MARKOVÁ, 2006b, p. 133), ou seja, é possível perceber que os respondentes se identificam com tradições, instituições, ideologias, etc. e permitem que elas falem por meio deles:

Prof. 1: Fala-se muito em globalização, e assim, cada vez mais com o advento da Internet, tudo fica muito fácil. Você acessa o mundo muito facilmente. Assim, o inglês acabou sendo uma língua, meio que universal, pelo fato de muitas pessoas estudarem. Então, esse é dado de pesquisas, têm aí pelo menos uns $60 \%, 70 \%$, senão mais, das transações comerciais sendo feitas em inglês por não nativos, então, é mais fácil aprender o inglês do que, por exemplo, o grego. Então, assim, isso acabou facilitando esse ensino em todos os países do mundo.

3 As entrevistas foram gravadas, transcritas e textualizadas.

Rev. Diálogo Educ., Curitiba, v. 8, n. 23, p. 55-70, jan./abr. 2008 
Prof. ${ }^{a}$ 2: Agora é importante porque todos os canais de comunicação hoje em dia, a TV a cabo, por exemplo, você quer assistir um seriado, é em inglês. Você quer assistir um jornal internacional, está em inglês, não é? Então, é importante para a vida, por causa disso: para informação.

Outro aspecto importante, também problematizado pelos professores entrevistados, diz respeito à idéia de que a "predisposição ao inglês" é decisiva para o sucesso ou não do aprendizado, uma das razões pelas quais acreditam nas possibilidades do ensino que ocorre em Institutos de Idiomas:

Prof. 1: [...] [é preciso] tentar convencer o aluno que o inglês é importante...

Prof. ${ }^{\text {2 }}$ 2: Na faculdade, muita gente faz o curso porque quer o diploma, então, assim, os interesses são diversos. [...] Mesmo no curso de Letras, porque muitos alunos falam o seguinte: 'eu queria só fazer português, eu não queria que tivesse [que estudar] inglês'.

Prof. 1: [...] no curso livre, o que eu sinto é [...] que a pessoa vem motivada pra estudar, então eu tenho o silêncio, eu tenho a atenção, eu tenho a participação.

Prof. ${ }^{\text {a }}$ 2: [...] Todo mundo que faz matrícula pra curso livre, de qualquer língua que seja, faz porque quer aprender.

Para os entrevistados, a fluência do idioma é o requisito mais importante para o sucesso na profissão, fluência que pode ser obtida num curso livre ou em uma viagem prolongada ao exterior. O papel da Universidade é visto como secundário e mais ligado à questão de empregabilidade do que propriamente no processo de formação docente. A docência, para eles, é resultado de "dom", de vocação:

Prof. 1: "Então, eu acho assim, que o primeiro é o dom, depois é a prática, a prática/experiência. [...] Agora, em nível de mercado eu acredito que um diploma universitário é importante para abrir caminhos, pra pessoa conseguir uma boa colocação e principalmente no ensino formal..."

Prof." 2: "Para ser um profissional da área? Sem o dom não tem nada! Eu acho a primeira coisa a pessoa tem quer ter o dom. A gente tem casos de profissionais que 
nem se formaram na área, mas tem o dom para dar aula e que foram buscar então só esse complemento de um curso de Letras. [...] Bom, a Universidade também é importante, porque você vai estudar outros aspectos que não a língua $[\ldots]$ você vai aprender outras coisas na universidade, como na área de didática, os PCNs, coisas importantes para você poder atuar como docente."

Ao conferir à docência uma afiliação, identificando-a com "dom", na verdade se está também fazendo um julgamento, estigmatizando-a, o que implica uma determinada atitude em relação a ela e em relação aos próprios cursos que formam professores, como o caso das Licenciaturas, no caso, das Licenciaturas em Letras.

Considerando as discussões precedentes, pode-se dizer que a representação social dos professores sobre o inglês como instrumento de comunicação e ascensão social orienta suas decisões em relação ao próprio processo formativo profissional, apontando para uma ênfase no domínio do conteúdo em detrimento à ênfase numa postura mais reflexiva e crítica do ser professor de inglês.

Assim, tais discussões parecem apontar para a importância de uma reflexão sobre processos formativos, sobre o valor atribuído pelos professores de inglês aos conhecimentos e habilidades específicos do profissional responsável pelo ensino de inglês, e sobre a maneira como eles estão sendo obtidos nas Licenciaturas.

\section{Apontando algumas conclusões}

Um aspecto importante a ser resgatado como conclusão é que a formação de professores de línguas prioriza discussões sobre o que fazer em sala de aula, não havendo muito espaço para a discussão sobre o porquê se trabalha de uma determinada maneira e não de outra, ou por que se ensina uma língua estrangeira moderna e não outra. O espaço de formação em serviço é praticamente inexistente e quando existe é geralmente usado de forma utilitária, não havendo formação crítica. Esta prática denota uma visão do professor como um executor, um aplicador do método, afastado das grandes decisões pedagógicas e denota também uma visão da língua inglesa como instrumento de aprimoramento técnico e profissional e não como um meio para ampliar a formação cultural dos cidadãos.

Resgatando o sentido de socialização profissional a partir de Bourdoncle (1991, p. 12) e as sutilezas no entendimento da profissão, o profissionalismo pode ser a melhor estratégia para a autonomia profissional do professor, porque vai permitir-lhe uma atuação crítica, assumida com autonomia. Contudo, a ideologia do "dom" é ainda um ranço persistente entre as perspectivas

Rev. Diálogo Educ., Curitiba, v. 8, n. 23, p. 55-70, jan./abr. 2008 
de o professor assumir o seu trabalho como profissão ou como vocação, ou, nas palavras de Boing (2007), "O profissionalismo, de acordo com a definição de Bourdoncle, pode ser uma perspectiva interessante para se trabalhar esse impasse. Se o trabalho for assumido profissionalmente, como uma escolha pessoal e livre pelo magistério, o professor fica além dessa polêmica que persiste entre vocação e profissão."

Pensar uma licenciatura que promova a autonomia e o comprometimento profissionais é um enorme desafio e foi nesse sentido que este artigo pretendeu trazer contribuições ao oferecer uma possibilidade de reflexão para aqueles que estão empenhados em buscar um novo modelo de formação de professores de inglês no qual saberes, crenças e práticas possam ser revisitados e reconstruídos.

\section{REFERÊNCIAS}

ADORNO, T. W. Educação e emancipação. Tradução de Wolfgang, L. M. São Paulo: Paz e Terra, 1995.

ALARCÃO, Isabel. O outro lado da competência comunicativa: a do professor. In: FAZENDA, I. C. A. (Org.). Didática e interdisciplinaridade. Campinas: Papirus, 1998. p. 21-28.

BIAZZOTO, Vera Lúcia Aparecida. Eu já dou aulas de inglês! A formação do aluno-professor no curso de Letras. 2004. Dissertação (Mestrado em educação) - Universidade Metodista de São Paulo, São Paulo, 2004.

BOING, Luiz Alberto. A profissionalização docente. In: Centro Pedagógico Pedro Arrupe. 2007. Disponível em: <www.pedroarrupe.com.br>. Acesso em: 08 jun. 2007.

BRANCO, Ademar Soares Castelo. Representações sobre o processo de ensino-aprendizagem de língua inglesa de alunos iniciantes de um curso de Letras. 2005. Dissertação (Mestrado em Lingüística Aplicada e Estudos da Linguagem) - Pontifícia Universidade Católica de São Paulo, São Paulo, 2005.

BRASIL. Presidência da República. Lei 9394/96, de 20/12/1996. Estabelece as diretrizes e bases da educação nacional. Diário Oficial da União, Brasília, ano134, n. 248, p. 27833-41, dez. 1996.

Rev. Diálogo Educ., Curitiba, v. 8, n. 23, p. 55-70, jan./abr. 2008 
BRASIL. Presidência da República. Lei n. 5692/71, 11/08/1971. Estabelece as diretrizes e bases da educação nacional. Diário Oficial da União, Brasília: Congresso Nacional, 1971.

BRASIL. Secretaria de Educação Fundamental. Parâmetros Curriculares Nacionais: $3^{\circ}$ e $4^{\circ}$ ciclos do ensino fundamental: língua estrangeira. Brasília: MEC/SEF, 1998.

CHIMIM, Renata. O fazer, o saber e o ser: reflexões de/sobre professores de inglês de uma escola de idiomas. 2003. Dissertação (Mestrado em Lingüística Aplicada e Estudos da Linguagem) - Pontifícia Universidade Católica de São Paulo. São Paulo, 2003.

DURAN, Marília Claret Geraes; JÚLIO, Maria Lúcia Monteiro. Repensando o curso (noturno) de pedagogia de uma instituição particular. In: REUNIÃO ANUAL DA ANPEd, 20., Caxambu, 1997.

FRANCO, Maria Laura Puglisi Barbosa. Análise de conteúdo. Brasília: Plano, 2003.

GATTI, Bernardete Angelina. Formar professores: velhos problemas e as demandas contemporâneas. Revista da FAEEBA: Educação e contemporaneidade. Salvador, v. 12, n. 20, p. 473-477, jul./dez., 2003.

JODELET, Denise. Loucura e representações sociais. Tradução de Lucy Magalhães. Petrópolis: Vozes, 2005.

LÜDKE, Menga; BOING, Luiz Alberto. Caminhos da profissão e da profissionalidade docentes. Educação \& Sociedade, Campinas, v. 25, n. 89, p. 1159-1180, set./dez. 2004. Disponível em: <http:// www.cedes.unicamp.br>. Acesso em: junho de 2007.

MARKOVÁ, Ivana. On 'the inner alter' in dialogue. International Journal for Dialogical Science, v. 1, n. 1, p. 125-147, 2006 a.

. Dialogicidade e representações sociais: as dinâmicas da mente. Tradução de Hélio Magri Filho. Petrópolis: Vozes, 2006b.

MARZARI, Gabriela Quantrin. Do you have any experience abroad? O gênero entrevista de emprego em cursos livres de línguas. 2005. Dissertação (Mestrado em Letras) - Universidade Federal de Santa Maria. Santa Maria, 2005.

MOITA LOPES, Luiz Paulo da. Oficina de lingüística aplicada: a natureza social e educacional dos processos de ensino/aprendizagem de línguas. Campinas: Mercado de Letras, 1996. 
MOSCOVICI, Serge. A representação social da psicanálise. Rio de Janeiro: Zahar, 1978.

ORTIZ, Renato. Mundialização: saberes e crenças. São Paulo: Brasiliense, 2006.

PAIVA, Vera Lúcia Menezes. A LDB e a legislação vigente sobre o ensino e a formação de professor de língua inglesa. In: STEVENS, C. M. T; CUNHA, M. J. Caminhos e colheitas: ensino e pesquisa na área de inglês no Brasil. Brasília: UnB, 2003. p. 53-84.

SCHÖN, Donald. Educando o profissional reflexivo: um novo design para o ensino e aprendizagem. Tradução de Roberto Cataldo Costa. Porto Alegre, Rio Grande do Sul: Artmed, 2000.

SHULMAN, Lee. Those who understand: knowledge growth in teaching. Educational Researcher, v. 15, n. 2, p. 4-14, 1986.

Recebido: 20/07/2007

Received: 07/20/2007

Aprovado: 05/11/2007

Approved: $11 / 05 / 2007$

Rev. Diálogo Educ., Curitiba, v. 8, n. 23, p. 55-70, jan./abr. 2008 